\title{
Passive immunization with anti-oestradiol antibodies during the luteal phase of the menstrual cycle potentiates the perimenstrual rise in serum gonadotrophin concentrations and stimulates follicular growth in the cynomolgus monkey (Macaca fascicularis)
}

\author{
A. J. Zeleznik, J. S. Hutchison† and H. M. Schuler* \\ Departments of Physiology, and Obstetrics and Gynecology, The University of Pittsburgh School of \\ Medicine, Pittsburgh, PA 15261, and ${ }^{*}$ Department of Pathology, Magee-Womens Hospital,
} Pittsburgh, PA 15213, U.S.A.

\begin{abstract}
Summary. Three unilaterally ovariectomized cynomolgus monkeys, in which menstrual cycles were driven by pulsatile infusion of synthetic GnRH at a fixed frequency of 1 pulse $/ \mathrm{h}$, were provided with a continuous infusion of ovine anti-oestradiol $\gamma$-globulin beginning 13 days after ovulation and continuing for 7 days thereafter. Plasma concentrations of both FSH and LH rose at the start of the antibody infusion and remained elevated throughout the 7-day treatment regimen when compared with control (nonimmune $\gamma$-globulin-treated or untreated) animals. Morphometric examination of ovaries at the end of the experimental and control infusions revealed a significant difference $(P<0.05)$ in the average size of the largest non-atretic antral follicle in each of the experimental animals when compared with that of the control animals $(2.45 \pm 0.23$ vs $1.30 \pm 0.53 \mathrm{~mm})$. Collectively, the 3 control animals possessed 9 nonatretic antral follicles $>1.0 \mathrm{~mm}$ diameter, none of which exceeded a diameter of $2.0 \mathrm{~mm}$. In contrast, the experimental animals had 28 non-atretic follicles of $>1.0 \mathrm{~mm}$ diameter, 8 of which exceeded $2.0 \mathrm{~mm}$.

These observations are consistent with the hypothesis that oestrogen and progesterone are the primary agents responsible for the restraint of gonadotrophin secretion and preovulatory follicular growth during the luteal phase of the primate menstrual cycle.
\end{abstract}

\section{Introduction}

Follicular maturation proceeds to the preantral and early antral stages during the luteal phase of the menstrual cycle, but the final stages of preovulatory follicular growth do not occur (Block, 1951; Koering, 1969; Zeleznik et al., 1980; McNatty et al., 1983). Upon the regression of the corpus luteum, this block in folliculogenesis is removed and preovulatory follicular growth, which takes about 14 days to complete, occurs during the subsequent follicular phase. Baird et al. (1975) postulated that the secretion of both oestradiol and progesterone by the corpus luteum, via their resultant feedback inhibition on gonadotrophin secretion, is responsible for the block in preovulatory folliculogenesis. Consistent with this hypothesis are observations that augmentation of serum gonadotrophin concentrations by the administration of exogenous human menopausal gonadotrophin during the luteal phase in macaques rapidly restores preovulatory follicular growth (diZerega \& Hodgen, 1980; Zeleznik \& Resko, 1980). In contrast to the hypothesis of Baird et al. (1975), others have suggested that progesterone, or other elaborations of the corpus luteum, may

†Present address: Serono Laboratories, Inc., 280 Pond Street, Randolph, MA 02368, U.S.A. 
act directly at the ovarian level to inhibit gonadotrophin-dependent follicular maturation. Evidence for this suggestion is represented by observations that surgical removal of the corpus luteum during the mid-luteal phase of the macaque menstrual cycle is followed by the reinitiation of follicular growth which occurred, in some instances, in the absence of statistically significant increases in plasma concentrations of FSH and/or LH (Goodman et al., 1977). However, in other similar studies, there was clear evidence of elevations in gonadotrophin concentration after removal of the corpus luteum (Goodman \& Hodgen, 1979), thereby, making it difficult to rule out the possibility that the reinitiation of follicular growth was due to elevated gonadotrophins rather than removal of an intra-ovarian modulator. Furthermore, studies in humans (Baird et al., 1984) demonstrated a clear elevation in serum FSH and LH concentrations which preceded the initiation of follicular growth that follows the removal of the corpus luteum during the early, mid- or late luteal phase in women.

We have developed a model system in which both the feedback effects of steroids on gonadotrophin secretion can be modulated and spontaneous ovarian activity can be observed in the presence of an intact hypothalamic-pituitary-ovarian axis (Zeleznik et al., 1985a). In this model system, hypophysiotrophic input is controlled directly by the pulsatile administration of synthetic GnRH (Knobil, 1980), while feedback effects of oestradiol are modulated by passive immunization with anti-oestradiol antibodies, thus permitting removal of the gonadotrophin-suppressing actions of ovarian steroids without removing the ovary. In the present study, we have investigated the role of luteal steroids on the feedback regulation of gonadotrophin secretion and the cessation of follicular growth during the luteal phase of the menstrual cycle. For this purpose, the primary effects of progesterone on reducing LH pulse frequency (Soules et al., 1984) were overcome by the administration of synthetic GnRH at a frequency of 1 pulse per hour throughout the luteal phase while the feedback actions of oestradiol were overcome by the administration of anti-oestradiol antibodies. Ovarian responses were assessed by morphometric analysis of sizes of non-atretic antral follicles. Preliminary results have been presented in abstract form (Zeleznik et al., 1985b).

\section{Materials and Methods}

\section{Animals}

Adult $2-3 \mathrm{~kg}$ female cynomolgus monkeys (Macaca fascicularis) were purchased from Hazleton Research Animals (Reston, VA). To permit infusion of oestradiol antibodies and GnRH, each animal was equipped with two jugular catheters which were exteriorized through a headcap attached to the calvaria and connected to the cage with a three-channel swivel apparatus (Spalding Medical Products, Arroyo Grande, CA). One catheter was used to infuse anti-oestradiol or control $\gamma$-globulins, the other to infuse GnRH and collect blood samples. GnRH (lots A4-25 and 031-A-26) was dissolved in $0.01 \mathrm{M}$-acetic acid-saline at a concentration of $1 \mathrm{mg} / \mathrm{ml}$ then diluted to $4 \mu \mathrm{g} / \mathrm{ml}$ in sterile saline and infused as a 6-min pulse $(0.25 \mathrm{ml} / \mathrm{min})$ at a frequency of $1 \mathrm{pulse} / \mathrm{h}$. The $\mathrm{GnRH}$ infusion was controlled by a peristaltic pump (Minipuls 2, Gilson Medical Electronics, Inc, Middleton, WI), the activity of which was regulated by a programmable electric timer (Chrontrol LD-4, Lindburg Enterprises, San Diego, CA).

\section{$\gamma$-Globulin preparations}

Anti-oestradiol antiserum was obtained from a sheep which had been immunized with an oestradiol-6-BSA conjugate (Zeleznik et al., 1985a). Control serum was obtained from a non-immunized sheep. A $\gamma$-globulin fraction was prepared from each by ammonium sulphate precipitation (Williams \& Chase, 1967). For each batch, $500 \mathrm{ml}$ saturated $\left(\mathrm{NH}_{4}\right)_{2} \mathrm{SO}_{4}$ were added slowly to 1 litre serum at room temperature. After mixing for $30 \mathrm{~min}$, the solution was centrifuged and the supernatant decanted. The precipitate was dissolved $500 \mathrm{ml} 0.01 \mathrm{M}-\mathrm{PBS}, \mathrm{pH} 7.35$ and $250 \mathrm{ml}$ saturated $\left(\mathrm{NH}_{4}\right)_{2} \mathrm{SO}_{4}$ were added. The precipitation step was repeated four additional times. The final precipitate was dissolved in $300 \mathrm{ml}$ PBS and was dialysed for 5 days against PBS at $4^{\circ} \mathrm{C}$. Each $\gamma$-globulin fraction was prepared for infusion by successive filtrations through a Whatman GFD filter $(2 \cdot 7 \mu \mathrm{m}$ pore size), a Whatman GF/F filter $(0.7 \mu \mathrm{m}$ pore size), followed by sterilization through a $0.2 \mu \mathrm{m}$ Nalgene membrane filter unit. All filters were purchased from Fisher Scientific (Pittsburgh, PA).

The specificity of the anti-oestradiol antiserum, based upon oestradiol- $17 \beta$ having $100 \%$ reactivity, was oestrone $1 \%$, oestriol $0.5 \%$, and dihydroprogesterone, testosterone, androstenedione and diethylstilboestrol (DES) all $<0.1 \%$. The binding capacity of the filtered $\gamma$-globulin fraction, determined at $4^{\circ} \mathrm{C}$ by Scatchard analysis, was $1-5 \times 10^{-5} \mathrm{M}$; the affinity constant was $5 \times 10^{9} \mathrm{M}^{-1}$ (Zeleznik et al., 1985a). The antioestradiol $\gamma$-globulin fraction had minimal gonadotrophic activity in a mouse Leydig cell bioassay and failed to stimulate follicular maturation in 
macaques in which endogenous gonadotrophin secretion was suppressed by treatment with DES (Zeleznik et al., 198.5a).

\section{Experiment design}

Six animals participated in the study. Each animal was unilaterally ovariectomized 2-3 weeks before the start of the pulsatile GnRH infusion. Each animal received GnRH at a frequency of 1 pulse/h to stimulate follicular maturation, ovulation and luteal function. Blood samples were obtained daily between $08: 30$ and 10:30 $\mathrm{h}$ between successive GnRH pulses and plasma was frozen for hormone assays. Commencing 13 days after the mid-cycle oestrogen rise, 3 of the animals began to receive a continuous infusion of anti-oestradiol $\gamma$-globulin at a rate of $37.5 \mathrm{ml} /$ day for Days 13-14, $50 \mathrm{ml} /$ day for Days 15-16 and 75 ml/day for Days 17-20. Two of the control animals received an infusion of $\gamma$-globulin from non-immunized sheep exactly as the experimental group. The third control animal did not receive a $\gamma$-globulin infusion as a further control for any potential non-specific inhibitory effects of $\gamma$-globulin infusion. The remaining ovary of each animal was removed on Day 20, which would correspond to Day 4 of the next follicular phase, assuming a luteal-phase duration of 16 days.

\section{Morphometry}

Each ovary was fixed in Bouin's solution for $24 \mathrm{~h}$ and processed for routine paraffin-wax embedding. Ovaries were sectioned at $10 \mu \mathrm{m}$ thickness and serial sections were affixed to glass microscope slides, cleared and stained with haematoxylin and eosin. The diameters of antral follicles were measured with the aid of a computer-assisted morphometry program (Bioquant II, R\&M Biometrics, Nashville, TN). Every 4th section was observed and the perimeters of all non-atretic antral follicles were recorded. Individual follicles were identified on subsequent sections by constructing a hand-drawn representation of the location of antral follicle in each section. The maximum diameter of each follicle was then determined by dividing the maximum perimeter by $\pi$, with the assumption that the unrestricted shape of a follicle is a sphere. Criteria for judging a follicle to be atretic included degeneration of the oocyte, dissolution of the granulosa cell layer and the presence of numerous clusters of granulosa cells with pycnotic nuclei.

\section{Hormone assays}

Plasma LH concentrations were measured with an RIA developed by Peckham \& Tontala (1981) using NIH-LH-RP-I as standard, rabbit anti hCG (R-13) as first antibody and cynomolgus LH (WP-XV-63-2429) as trace. The minimum detectable plasma concentration was $9.10 \mathrm{mg} / \mathrm{ml}$ when $0.2 \mathrm{ml}$ plasma was used. FSH concentrations were measured by the RIA described by Belchetz et al. (1978) which uses a rabbit anti-human antiserum (batch 5, NIAMDD. National Pituitary Agency), human FSH (NIH-FSH-HS-1) as trace and rhesus FSH (WP-X111-21-42) as standard. The minimum detectable plasma FSH concentration was $\sim 3 \mathrm{ng} / \mathrm{ml}$ when $0.2 \mathrm{ml}$ plasma was used. All samples were measured in single assays and the intra-assay coefficients of variation for standard serum pools were $18 \%$ and $22 \%$ for the FSH and $\mathrm{LH}$ assays respectively.

Plasma oestradiol-17 $\beta$ and progesterone concentrations were measured by RIAs as described previously (Zeleznik \& Resko, 1980). The minimum detectable oestradiol- $17 \beta$ concentration was $30 \mathrm{pg} / \mathrm{ml}$ when $0.1 \mathrm{ml}$ serum was used. The interassay coefficient of variation was $16 \%$ for a serum pool containing $380 \mathrm{pg} / \mathrm{ml}$ and $24 \%$ for a serum pool containing $90 \mathrm{pg} / \mathrm{ml}$. The minimum detectable plasma progesterone concentration was $0.2 \mathrm{mg} / \mathrm{ml}$ when $0.05 \mathrm{ml}$ plasma was used. The intraassay coefficient of variation was $17 \%$ for a serum pool with $3.6 \mathrm{mg} / \mathrm{ml}$. For oestradiol measurements, when necessary, plasma samples were diluted with PBS which contained $0.1 \%$ gelatin before extraction.

\section{Statistics}

The diameter of the largest non-atretic antral follicle in each of the 3 experimental animals was compared with the diameter of the largest antral follicle in each of the 3 control animals for statistical significance by Student's $t$ test (Woolf, 1968). To assess the effects of passive immunization on the distribution of large antral follicles, we compared the diameters of the 10 largest non-atretic follicles in each of the control animals with the diameters of the 10 largest non-atretic follicles in each of the experimental animals by the non-parametric Mann-Whitney U-Test (Snedecor \& Cochran, 1967). For this analysis, we made the assumption that follicles at the early antral stage before selection of the preovulatory follicle occurs are independent of one another with respect to the initiation of growth as well as atresia.

\section{Results}

As shown in Fig. 1 the control animals exhibited typical luteal phases characterized by elevated progesterone and low gonadotrophin concentrations. Upon the demise of the corpus luteum, reflected by the fall in systemic progesterone concentrations on Days 13-15, plasma concentrations of both FSH and $\mathrm{LH}$ rose to about $10 \mathrm{ng} / \mathrm{ml}$ and $20 \mathrm{ng} / \mathrm{ml}$ respectively. Infusion of a $\gamma$-globulin fraction from non-immunized sheep on Days 13-20 did not influence either the onset of luteolysis or the subsequent perimenstrual rise in plasma gonadotrophin concentrations. 
Plasma FSH and LH concentrations in the experimental group were similar to those of the control group before the start of anti-oestradiol $\gamma$-globulin infusion. Thereafter, plasma concentrations of both FSH and $\mathrm{LH}$ rose strikingly and were maintained at elevated values throughout the $\gamma$-globulin infusion. Plasma oestradiol concentrations of the experimental group were similar to those of controls before infusion of anti-oestradiol $\gamma$-globulins. Thereafter, plasma oestradiol concentrations in passively immunized animals rose to $3-5 \mathrm{ng} / \mathrm{ml}$. Progesterone concentrations of the experimental group were slightly below those of controls throughout the luteal phase. This was due largely to one of the experimental animals which exhibited progesterone concentrations of $1-1.5 \mathrm{ng} / \mathrm{ml}$ throughout the luteal phase. (The ovary from the animal is shown in Fig. 2f.) Plasma progesterone concentrations declined to undetectable values $(<0.2 \mathrm{ng} / \mathrm{ml})$ in 2 of the experimental animals by Day 16, the expected time of luteal regression. Progesterone concentrations in the third antibody-treated animal rose to $5-7 \mathrm{ng} / \mathrm{ml}$ during the mid-luteal phase, then declined to $1.5 \mathrm{ng} / \mathrm{ml}$
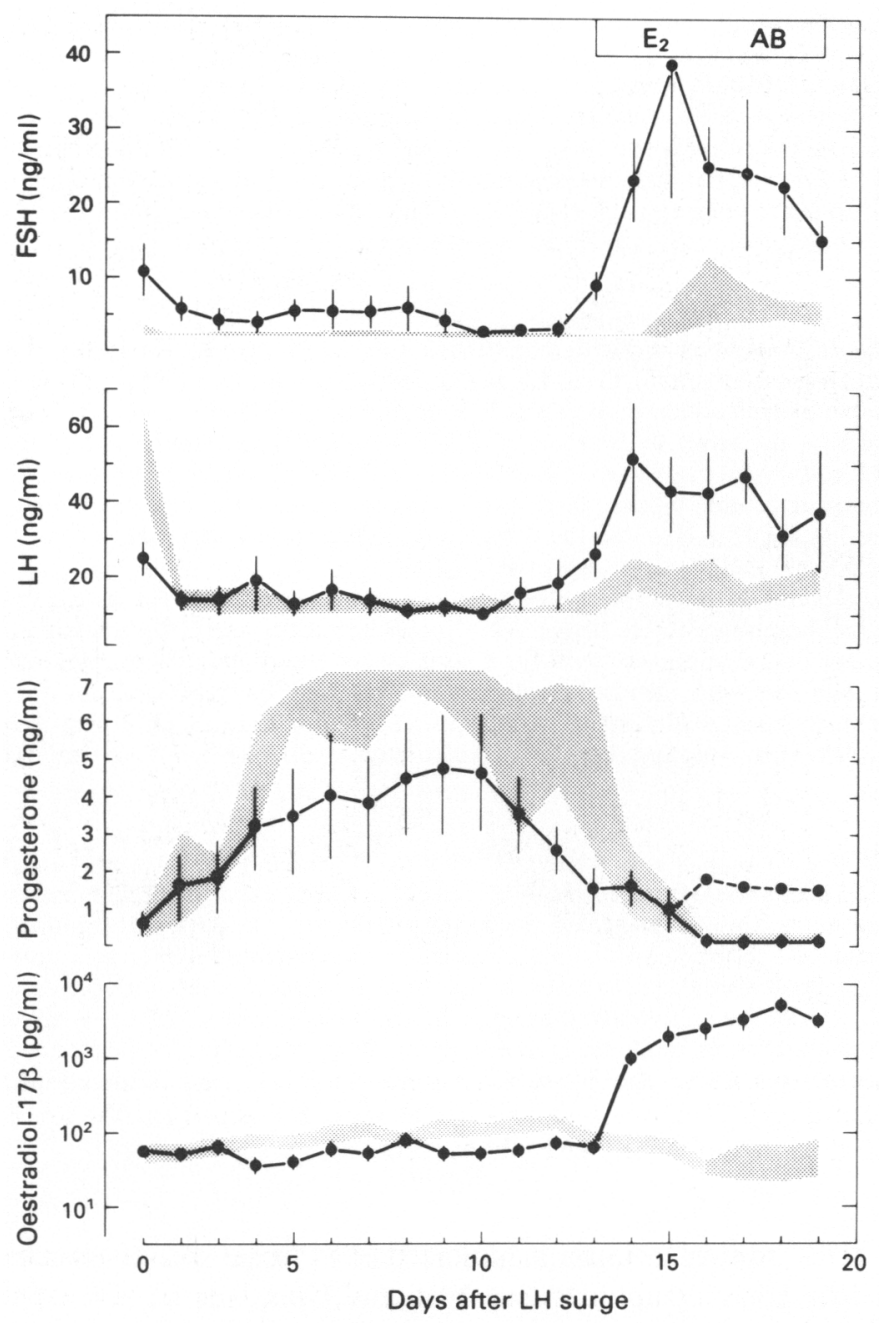

Fig. 1. Serum gonadotrophin and steroid concentrations in control and anti-oestradiol antibody-infused cynomolgus monkeys. The shaded areas depict 1 s.e. about the mean of values obtained from 3 control animals. The solid lines show means \pm 1 s.e. of values obtained from 3 experimental animals: $E_{2} A B$, duration of antibody infusion. 

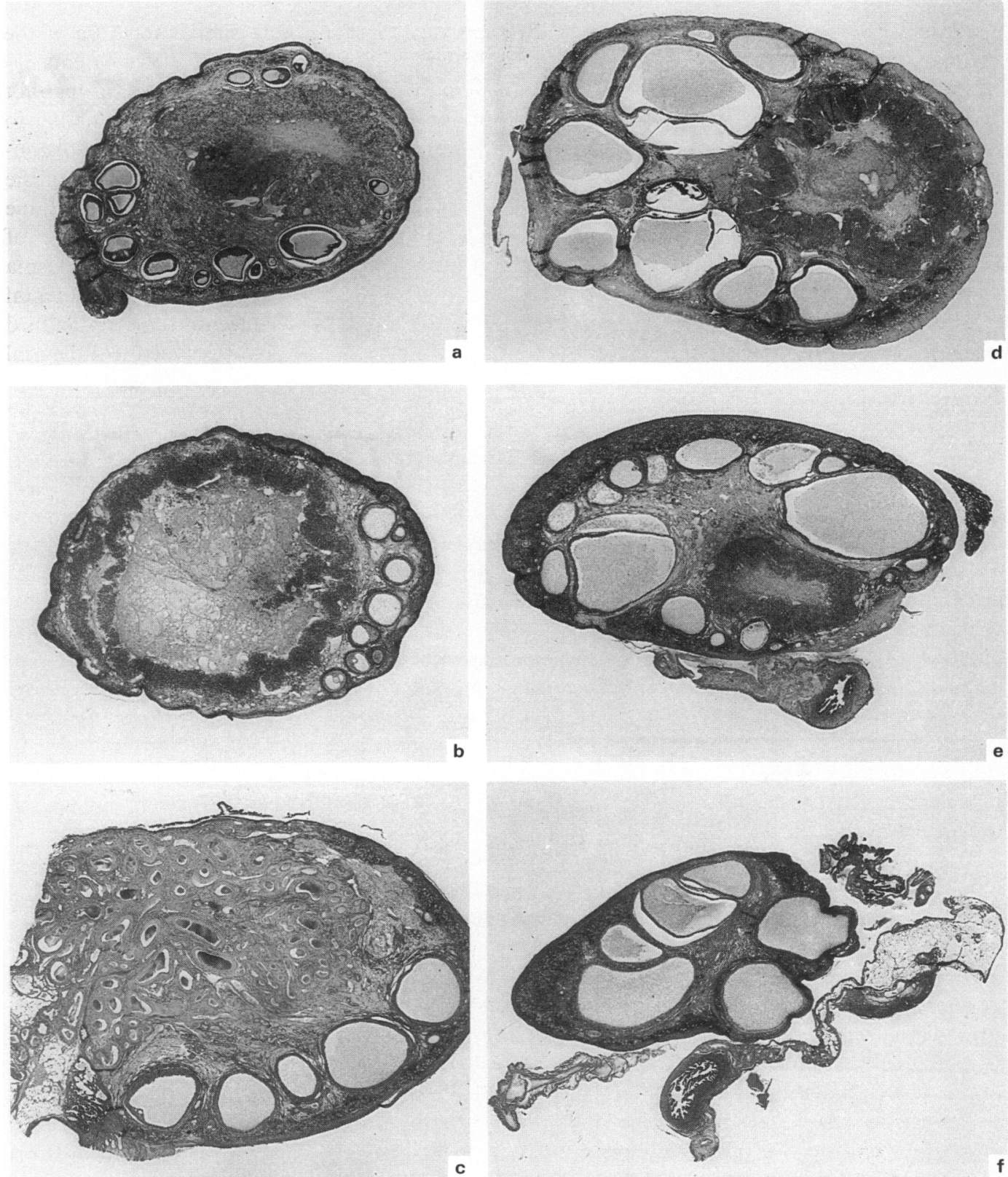

Fig. 2. Sections of ovaries of the 3 control animals (a, b, c), the 3 anti-oestradiol antibodytreated animals (d, e, $\mathrm{f}$ ). The ovary shown in (b) was obtained from the animal that did not receive a $\gamma$-globulin infusion. Haematoxylin \& eosin, $\times 6.5$.

by Day 13, when the antibody infusion was started. Thereafter, progesterone concentrations did not decline further and were maintained at $1.5 \mathrm{ng} / \mathrm{ml}$, well beyond the expected time of luteal regression (interrupted line, Fig. 1).

Figure 2 illustrates histological sections of ovaries, from control animals $(a-c)$ and experimental animals $(d-f)$, which were removed on Day 20 upon termination of the control or anti-oestradiol $\gamma$-globulin infusion. The ovaries of control animals were characterized by the presence of numerous 


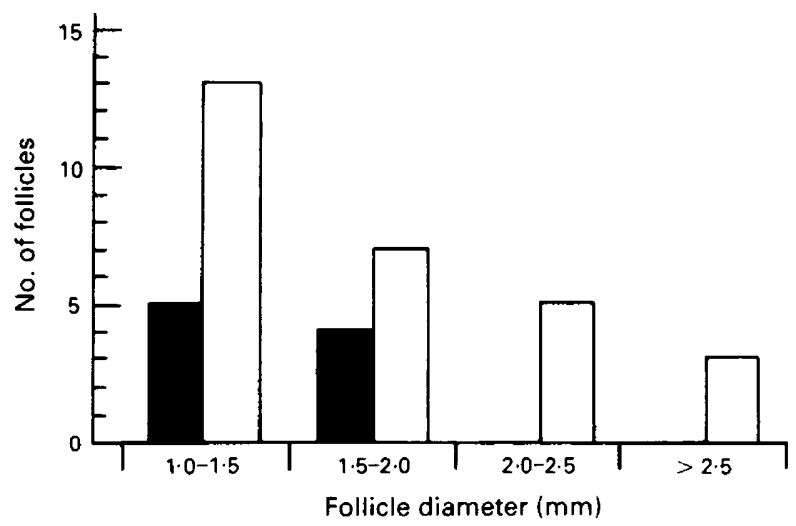

Fig. 3. Size distribution of large antral follicles from control (solid bars) and antibody-treated (open bars) animals. Each bar represents the total number of follicles from the 3 animals of each group. Note that there are no follicles $>2.0 \mathrm{~mm}$ diameter in the control group.

small antral follicles, typical of those usually seen during the early follicular phase. In contrast, each of the experimental animals possessed numerous larger antral follicles. Figure 3 summarizes the distribution of antral follicles with diameters $>1.0 \mathrm{~mm}$ from the control and experimental animals. Collectively, the control animals had 9 follicles greater than $1.0 \mathrm{~mm}$ diameter, none of which exceeded a diameter of $2.0 \mathrm{~mm}$. In contrast, the experimental animals had 28 follicles $>1.0 \mathrm{~mm}$ diameter, 9 of which exceeded $2.0 \mathrm{~mm}$. The average diameter of the largest antral follicle in each of the 3 experimental animals $(2.45 \pm 0.23 \mathrm{~mm}$, s.d.) was significantly greater $(P<0.05)$ than the average diameter of the largest follicle in each of the 3 control animals $(1.30 \pm 0.53 \mathrm{~mm}, \mathrm{s.d}$.). In addition, the sizes of the 30 largest non-atretic follicles ( 10 per animal) in the experimental group were significantly greater $(P<0.001)$ than those of the 30 largest follicles $(10$ per animal $)$ in the control group.

\section{Discussion}

In the current studies we provided GnRH at a fixed frequency of 1 pulse/h to offset the progesterone-mediated decrease in gonadotrophin pulse frequency and infused anti-oestradiol antibodies to reduce the gonadotrophin-suppressing actions of oestradiol and found that this treatment resulted in a potentiation of the perimenstrual rise in gonadotrophin concentrations with a concomitant stimulation of antral follicle growth. We conclude from these studies that the primary mechanism by which a functional corpus luteum interrupts follicular growth is by way of its suppression of gonadotrophin secretion by oestrogen and progesterone rather than by a direct inhibition of follicular growth (Goodman \& Hodgen, 1979). We did not attempt to measure or estimate bound and free oestrogen concentrations in vivo because of the difficulties in evaluating equilibrium binding in the presence of numerous binding proteins (albumin, testosterone-binding globulin, and anti-oestradiol antibodies) each with different affinities for oestrogen. According to the model of Dunn et al. (1981), it is likely that the introduction of anti-oestradiol antibodies to serum would not dramatically alter total protein binding of oestradiol but rather cause a redistribution of bound oestradiol from albumin and testosterone-binding globulin. However, we are confident that our results are direct consequence of inhibition of oestrogen action. First, we did not observe elevated gonadotrophin concentrations and stimulation of follicular growth in animals treated with control $\gamma$-globulins. Second, our previous studies (Zeleznik et al., 1985a) demonstrated that the endometrium of passively immunized animals is atrophic despite plasma oestrogen concen- 
trations in excess of $5 \mathrm{ng} / \mathrm{ml}$ indicating that the majority of oestrogen in these animals is unable to elicit a biological response.

It is well established from ovarian ablation and steroid replacement studies that oestradiol and progesterone exert strong suppressing actions on gonadotrophin secretion (Karsch et al., 1973b). However, attempts to establish the cause of the initiation of the perimenstrual rise in serum gonadotrophin concentrations and the role of this rise in gonadotrophin concentrations in stimulating follicular growth have not provided conclusive evidence that the cessation of steroid production by the corpus luteum is the primary cause for both the elevated gonadotrophin concentrations as well as the initiation of antral follicular growth. Resko et al. (1974) administered progesterone to rhesus monkeys during the late luteal phase into the subsequent early follicular phase and found that this treatment did not suppress the rise in FSH and LH concentrations at the time of luteal regression. Goodman et al. (1977), in their studies involving removal of the corpus luteum were unable, in many cases, to document statistically significant increases in serum FSH and $\mathrm{LH}$ concentrations despite large decreases in serum oestradiol and progesterone concentrations. However, in the study of Resko et al. (1974), although not statistically significant, LH concentrations in progesterone-treated groups were only $20 \%$ of values measured in cholesteroltreated control animals. Similarly, in many of the studies of Goodman et al. (1977) and Goodman \& Hodgen (1979), serum FSH concentrations appeared to be elevated transiently after the removal of the corpus luteum. Based upon observations in humans and rhesus monkeys, it is likely that changes in gonadotrophin concentrations in the range of $20-30 \%$ may be effective in either stimulating (Brown, 1978) or inhibiting (Zeleznik, 1981) follicular growth. Such changes of this magnitude may fall outside the resolution of conventional radioimmunoassays.

In our current experiments, we maintained LH pulse frequency at 1 pulse/h throughout the entire luteal phase, whereas in spontaneous menstrual cycles, the LH pulse frequency decreases to approximately 1 pulse every $4-8 \mathrm{~h}$ as the luteal phase progresses (Ellinwood et al., 1984). It is likely that the progressive decrease in LH pulse frequency during the spontaneous luteal phase is due to a deceleration of pulsatile GnRH secretion which is mediated by progesterone (Soules et al., 1984). Accordingly, our studies do not allow us to determine the relative importance of progesterone versus oestradiol in suppressing gonadotrophin secretion during the luteal phase. Previous studies on macaques by Pohl et al. (1983) have shown that a GnRH pulse frequency of 1 pulse/3 h is unable to stimulate follicular growth and oestrogen secretion, indicating that a reduction in GnRH pulse frequency per se is able to arrest follicular development. However, maintenance of rhesus or cynomolous monkeys on an unvarying GnRH pulse frequency of 1 pulse/h throughout the luteal phase does not appear to shorten the next follicular phase, demonstrating that a decrease in pulse frequency during the luteal phase is not required to restrain follicular growth. On the basis of these observations, it is likely that the combined secretions of oestradiol and progesterone provide a fail-safe mechanism to suppress gonadotrophin secretion and arrest follicular maturation during the luteal phase. As shown by our current studies, in the absence of a decrease in LH pulse frequency, oestradiol is able to suppress gonadotrophin secretion and folliculogenesis whereas in the apparent absence of oestradiol, progesterone alone appears to suppress follicular growth by decreasing gonadotrophin pulse frequency (Pohl et al., 1983).

Lastly, in one of our passively immunized animals serum progesterone concentrations were maintained beyond the expected 15-16-day duration of the luteal phase. This observation, albeit in a single animal, is intriguing in that it has long been speculated that oestradiol may be a luteolysin in primates (Karsch et al., 1973a). The use of passive immunization throughout the entire luteal phase may provide further insights regarding the luteolytic actions of oestradiol.

Supported by NIH grants HD 12014 and HD-08610 and Research Career Development Award HD-00531 to A.J.Z. We thank the National Hormone and Pituitary Program for GnRH: $\mathrm{Mr}$ Anthony Battelli for help with care of animals; and Mr William Jones and Mrs Heidi Wentzel for RIAs. 


\section{References}

Baird, D.T., Baker, T.G., McNatty, K.P. \& Neal, P. (1975) Relationship between the secretion of the corpus luteum and the length of the follicular phase of the ovarian cycle. J. Reprod. Fert. 45, 611-619.

Baird, D.T., Backstrom, T., McNeilly, A.S., Smith, K.S. \& Wathen, C.G. (1984) Effects of enucleation of the corpus luteum at different stages of the luteal phase of the human menstrual cycle on subsequent follicular development. J. Reprod. Fert. 70, 615624.

Belchetz, P.E., Plant, T.M., Nakai, Y., Keogh, E.J. \& Knobil, E. (1978) Hypophyseal responses to continuous and intermittent delivery of hypothalamic gonadotropin releasing hormone. Science, N.Y. 202, $631-633$.

Block, E. (1951) Quantitative morphological investigation of the follicular system in women: variation in the different phases of the sexual cycle. Acta endocr., Copenh. 8, 33-54.

Brown, J.B. (1978) Pituitary control of ovarian functionconcepts derived from gonadotropin therapy. Aust. NZ. J. Obstet. Gynaecol. 18, 46-54.

diZerega, G.S. \& Hodgen, G.D. (1980) Cessation of folliculogenesis during the primate luteal phase. J. clin. Endocr. Metab. 51, 158-160.

Dunn, J.F., Nisula, B.C. \& Rodbard, D. (1981) Transport of steroid hormones: Binding of 21 endogenous steroids to both testosterone-binding globulin and corticosteroid-binding globulin in human plasma. $J$. clin. Endocr. Metab. 53, 58-68.

Ellinwood, W.E., Norman, R.L. \& Spies, H.G. (1984) Changing frequency of pulsatile luteinizing hormone and progesterone secretion during the luteal phase of the menstrual cycle of rhesus monkeys. Biol. Reprod. 31, 714-722.

Goodman, A.L. \& Hodgen, G.D. (1979) Between-ovary interaction in the regulation of follicle growth, corpus luteum function and gonadotropin secretion in the primate ovarian cycle. II. Effects of luteectomy and hemiovariectomy during the luteal phase in cynomolgus monkeys. Endocrinology 104, $1310-1316$.

Goodman, A.L., Nixon, W.E., Johnson, D.K \& Hodgen, G.D. (1977) Regulation of folliculogenesis in the cycling rhesus monkey: selection of the dominant follicle. Endocrinology 100, 155-161.

Karsch, F.J., Krey, L.C., Weick, R.F., Dierschke, D.J. \& Knobil, E. (1973a) Functional luteolysis in the rhesus monkey: the role of estrogen. Endocrinology 92, 1148-1152.

Karsch, F.J., Weick, R.F., Hotchkiss, J., Dierschke, D.J. \& Knobil, E. (1973b) An analysis of the negative feedback control of gonadotropin secretion utilizing chronic implantation of steroids into ovariectomized rhesus monkeys. Endocrinology 93, 478-486.

Knobil, E. (1980) The neuroendocrine control of the menstrual cycle. Recent Prog. Horm. Res. 36, 53-88.

Koering, M.J. (1969) Cyclic changes in ovarian morphology during the menstrual cycle in Macaca mulaita. Am. J. Anat. 126, 73-101.
McNatty, K.P., Hillier, S.G., van den Boogaard, A.J.M., Trimbos-Kemper, T.C.M., Reichert, L.E., Jr \& van Hall, E.V. (1983) Follicular development during the luteal phase of the human menstrual cycle. J. clin. Endocr. Metab. 56, 1022-1031.

Peckham, W.D. \& Tontala, F.J. (1981) A new radioimmunoassay for monkey luteinizing hormone. Biol. Reprod. (Suppl.) 28, 119A, Abstr. 193.

Pohl, C.R., Richardson, D.W., Hutchison, J.S., Germak, K.J.A. \& Knobil, E. (1983) Hypophysiotropic signal frequency and the functioning of the pituitaryovarian system in the rhesus monkey. Endocrinology 112, 2076-2080.

Resko, J.A., Norman, R.L., Niswender, G.D. \& Spies, H.G. (1974) The relationship between progestins and gonadotropins during the late luteal phase of the menstrual cycle in rhesus monkeys. Endocrinology 94 , 128-135.

Snedecor, G.W. \& Cochran, W.G. (1967) Statistical Methods, 5th edn, p. 130. Iowa State University Press, Ames.

Soules, M.R., Steiner, R.A., Clifton, D.K., Cohen, N.L., Askel, S. \& Bremner, W.J. (1984) Progesterone modulation of pulsatile luteinizing hormone secretion in normal women. J. clin. Endocr. Metab. 58, 378-383.

Williams, C.A. \& Chase, M.W. (1967) Methods in Immunology and Immunochemistry, Vol. 1. Academic Press, New York.

Woolf, C.M. (1968) Principles of Biometry. D. Van Nostrand Co., Inc., Princeton.

Zeleznik, A.J. (1981) Premature elevation of systemic estradiol reduces serum levels of follicle stimulating hormone and lengthens the follicular phase of the menstrual cycle in rhesus monkeys. Endocrinology 109, 352-355.

Zeleznik, A.J. \& Resko, J.A. (1980) Progesterone does not inhibit gonadotropin-induced follicular maturation in the female rhesus monkey. Endocrinology 106, 1820-1826.

Zeleznik, A.J., Wildt, L. \& Schuler, H.M. (1980) Characterization of ovarian folliculogenesis during the luteal phase of the menstrual cycle in thesus monkeys using $\left({ }^{3} \mathrm{H}\right)$ thymidine autoradiography. Endocrinology 107 , 982-988.

Zeleznik, A.J., Hutchison, J.S. \& Schuler, H.M. (1985a) Interference with the gonadotropin-suppressing actions of estradiol in macaques overrides the selection of a single preovulatory follicle. Endocrinology 117, 991-999.

Zeleznik, A.J., Hutchison, J.S. \& Schuler, H.M. (1985b) Investigation of the mechanisms responsible for the suppression of follicular growth during the luteal phase of the primate menstrual cycle. Biol. Reprod. (Suppl). 32, 133, Abstr. 191. 